\title{
Экспериментальные исследования модификации характеристик GaAs-структур с контактами Шоттки после воздействия быстрых нейтронов
}

\author{
(C) Е.В. Волкова ${ }^{1}$, А.Б. Логинов ${ }^{2}$, Б.А. Логинов ${ }^{3}$, Е.А. Тарасова ${ }^{1}$, А.С. Пузанов ${ }^{1}$, С.А. Королев ${ }^{4}$, \\ E.C. СемёновыX ${ }^{1}$, С.В. Хазанова ${ }^{1}$, С.В. Оболенский ${ }^{1}$ \\ ${ }^{1}$ Нижегородский государственный университет им. Н.И. Лобачевского, \\ 603950 Нижний Новгород, Россия \\ ${ }^{2}$ Московский государственный университет им. М.В. Ломоносова, \\ 119991 Москва, Россия \\ ${ }^{3}$ Национальный исследовательский университет „Московский институт электронной техники“ (МИЭТ), \\ 124498 Зеленоград, Москва, Россия \\ ${ }^{4}$ Институт фризики микроструктур Российской академии наук, \\ 603950 Нижний Новгород, Россия \\ E-mail: tarasova@rf.unn.ru; loginov@mail.ru \\ Поступила в Редакцию 12 апреля 2021 г. \\ В окончательной редакции 19 апреля 2021 г. \\ Принята к публикации 19 апреля 2021 г.
}

Исследуются электрофизические параметры и морфология поверхности структур $n / n^{-}$GaAs с контактами Шоттки до и после воздействия нейтронов со средней энергией $\sim 1$ МэВ. Методом вольт-фарадных измерений определены изменения профилей концентрации и подвижности электронов в структурах. Методом атомно-силовой микроскопии выявлены возникающие при облучении кластеры радиационных дефектов, предложен комплексный подход к определению их параметров.

Ключевые слова: GaAs-структура, контакты Шоттки, быстрые нейтроны.

DOI: $10.21883 /$ FTP.2021.10.51431.19

\section{1. Введение}

Известно, что взаимодействие излучения с твердым телом сопровождается созданием различного рода структурных нарушений в кристаллической решетке $[1,2]$. При облучении реакторными нейтронами в результате каскадных смещений атомов материала из узлов решетки, помимо точечных дефектов и их комплексов, образуются их скопления - кластеры радиационных дефектов (КРД) [1,3,4]. Такие трехмерные нарушения окружены пространственным зарядом и являются непрозрачными или частично прозрачными для электронов включениями (второй вариант реализуется в случае выраженного деления кластеров на более мелкие субкластеры, которых в одном КРД может быть 5-10 штук и более [1]) [4]. Характерные размеры КРД составляют десятки и сотни нанометров, что сравнимо с размерами активных областей современных приборов наноэлектроники, поэтому наличие кластеров может оказывать значительное влияние на протекание тока в активной области прибора. В связи с этим вопросы определения количества и размеров КРД (с учетом их областей пространственного заряда), а также степени „рыхлости“ их внутренней структуры крайне важны при проектировании радиационно стойких полупроводниковых приборов.

Особую значимость вопросы морфологии кластеров радиационных дефектов приобретают в случае реализации приборов наноэлектроники, размеры которых могут быть сопоставимы с размерами кластеров, а также с расстояниями между ними и между субкластерами. Поэтому необходимо оценивать характерные размеры непрозрачных для электронов включений и характерные расстояния между ними, а также определять значение концентрации и подвижности электронов в пространстве между кластерами, т.е. там, где носители могут создавать электрический ток после облучения. Эти исследования было важно реализовать на одном и том же экспериментальном образце, чтобы исключить влияние разброса параметров исследуемых образцов, неоднородностей облучения и других паразитных факторов, повышающих погрешность экспериментальных данных.

Для решения подобной задачи в работе предложено проводить комплексные исследования, включающие в себя анализ микрорельефа поверхности с использованием методики атомно-силовой микроскопии и вольтфарадные измерения. Были подобраны образцы, в которых приповерхностный слой полупроводника размером $\sim 100$ нм содержал в среднем только один слой кластеров дефектов, и именно эту область можно было исследовать как методом зондовой микроскопии со стороны поверхности, так и с помощью вольт-фарадного метода в пространстве между кластерами.

\section{2. Вольт-фарадные измерения}

В данной работе приводятся результаты экспериментального исследования воздействия реакторных нейтро- 
нов на GaAs-структуры. Исследование проводилось на основе анализа модификации топографии поверхности и электрофизических параметров структур $n / n^{-}$-GaAs. Образцы были изготовлены методом газофазной эпитаксии (НПП „Салют“, Нижний Новгород). Для удобства измерений и снижения их погрешности комплект круговых и кольцевых измерительных диодов объединяли в тестовый объект, предназначенный для определения профилей распределения электронов по глубине и оценки их подвижности (рис. 1) [5].

Измерения проводились до и после облучения быстрыми нейтронами со следующими характеристиками излучения: колоколообразный спектр, изотропность, средняя энергия $\sim 1 \mathrm{MэВ,} \mathrm{флюенс} \sim 5 \cdot 10^{14} \mathrm{~cm}^{-2}$. Часть образцов после образования радиационных дефектов подвергалась отжигу посредством быстрого разогрева до температуры $200^{\circ} \mathrm{C}$ и выдержки около 1 суток с плавным снижением температуры до комнатной, что в некоторых случаях позволяло избавиться от мелких дефектов и их скоплений. Анализ морфологии образовавшихся кластеров проводился по результатам исследований микрорельефа поверхности структуры в зазорах между контактами (рис. 1) с помощью методики зондовой микроскопии; распределение концентрации электронов по глубине структуры и их подвижность до и после облучения исследовались с применением вольтфарадного метода [5]. Использование набора диодов с разными геометрическими размерами позволяло исключить влияние паразитных сопротивлений и краевых эффектов, присущих такого рода измерениям [5].

Профиль концентрации по глубине имел колоколообразный вид - значение концентрации в 1.5-2 раза увеличивалось в $n$-слое близи границы раздела $n$ - и $n^{-}$-слоев, а затем снижалось на $1.5-2$ порядка. Ис-

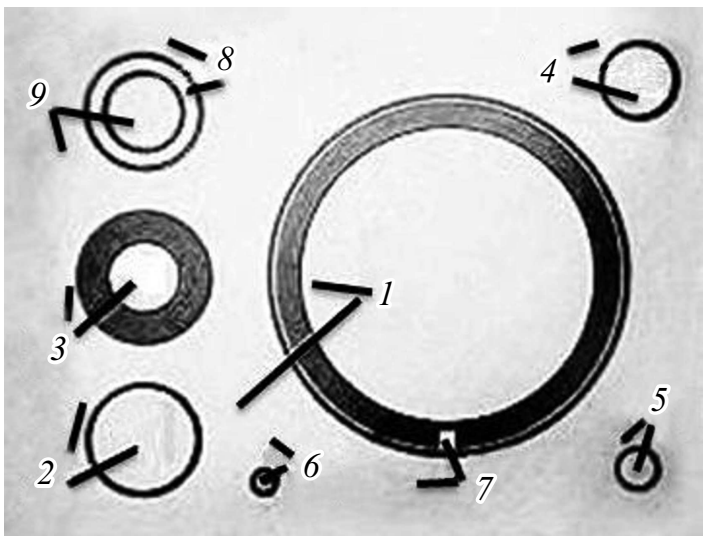

Рис. 1. Исследуемый тестовый объект с круговыми и кольцевыми диодами Шоттки. Радиусы круговых и ширина кольцевых контактов диодов составляли от 9 до 300 мкм. Номерами показаны пары контактов, которые использовались для измерений. Благодаря значительно (в 100 раз и более) различающейся площади контактов в подобранных парах можно было использовать только барьерные контакты, так как емкость последовательного включения двух барьерных контактов определялась меньшей емкостью.

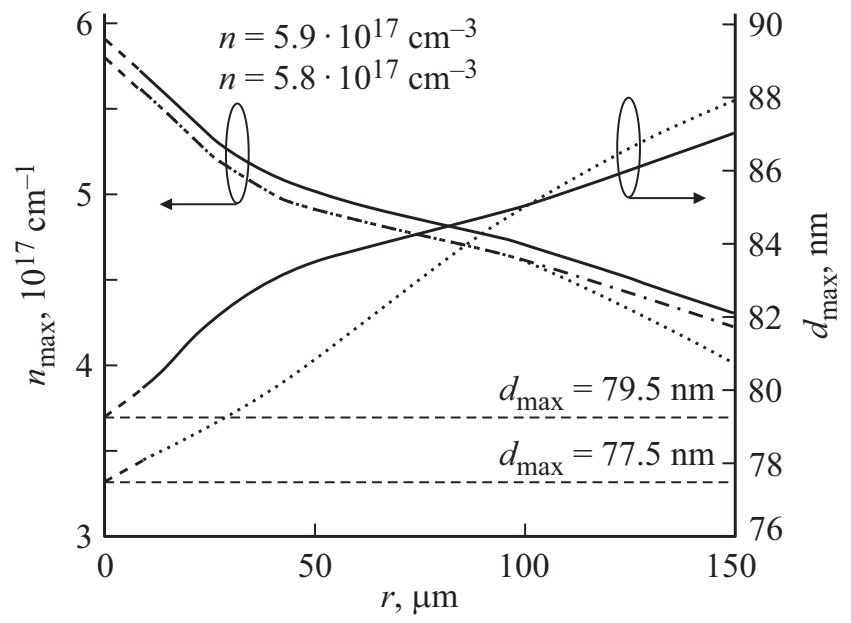

Рис. 2. Зависимость максимального значения в профиле концентрации $n_{\max }$ и координаты $d_{\max }$, соответствующей максимуму профиля концентрации электронов, от радиуса кругового и ширины кольца кольцевого контактов $(r)$ диодов: сплошная линия - до облучения, точечная - после облучения нейтронами $0.5 \cdot 10^{15} \mathrm{~cm}^{-2}$ и последующего отжига, штрихпунктирная аналитический расчет.

следовались как уменьшение концентрации электронов в слоях после радиационного облучения из-за захвата электронов комплексами радиационных дефектов, так и смещение максимума распределения концентрации. Кроме этого оценивалась подвижность электронов в слоях.

Зависимости максимального значения концентрации носителей заряда $n_{\max }$ и положения указанного максимума по глубине структуры $d_{\max }$ от размера тестовых диодов - ширины кольцевого и радиуса кругового контактов - приведены на рис. 2. При уменьшении характерных размеров контактов можно уточнять значения, так что экстраполяция размеров контактов до нуля, что соответствует идеальному гипотетическому контакту, дает искомое истинное значение и положение максимума концентрации.

С использованием описанной в [5] методики было найдено значение максимальной концентрации электронов $n_{\max }$ в структуре до облучения, которое составило $5.9 \cdot 10^{17} \mathrm{~cm}^{-3}$, сам максимум распределения располагался на глубине структуры $d_{\max }=79.5$ нм. После облучения указанные значения составили $5.8 \cdot 10^{17} \mathrm{~cm}^{-3}$ и 77.5 нм соответственно (рис. 2). Подвижность электронов снизилась на $10-20 \%$.

\section{3. Измерения на атомно-силовом микроскопе}

Для исследований микрорельефа поверхности GaAsструктуры до и после воздействия быстрых нейтронов использовался сканирующий зондовый микроскоп „СММ-2000“ (изготовитель - АО „Завод ПРОТОН“, г. Зеленоград, www.microscopy.su). Применение специальной методики позиционирования образцов [6] позво- 
ляло констатировать наличие связи нарушений, появившихся на поверхности структур, с воздействием нейтронного излучения, поскольку исследования рельефа поверхности проводились в одной и той же области до и после облучения [7]. Это достигалось закреплением образцов на специальной ламели, позволяющей многократно размещать образцы в фиксирующем устройстве микроскопа одинаковым образом [8]. Облучение образцов осуществлялось вместе с ламелью, на которой они были приклеены.

Топография поверхности в области GaAs-колец диодов и транзисторов исследовалась в режиме атомносиловой микроскопии (АСМ). В качестве зондовых датчиков использовались кантилеверы марки „MSNL“ фирмы Brucker, США, имеющие радиус закругления острия 2 нм. Достигаемое разрешение составляло до 2 нм по латеральным и до 0.1 нм по нормальным размерам рельефа. Для одновременного с рельефом снятия карт электропроводности исследуемой поверхности с разрешением до 5 нм применялись также проводящие кантилеверы RTESPA фирмы Brucker, США, с радиусом закругления острия 8 нм. Дополнительные измерения проводились с использованием кантилеверов с радиусом закругления острия 10 нм марки NSG30/TiN фирмы NT-MDT.

Характерный вид изображений, полученных при сканировании поверхности GaAs до и после нейтронного воздействия, представлен на рис. 3. Из рисунка следует, что качественный вид „зерен“ GaAs сохраняется, но на сканах облученного материала появляются включения существенно меньшего размера. Средняя поверхностная плотность выявленных объектов составляет $1.2 \mathrm{M \kappa м}^{-2}$.
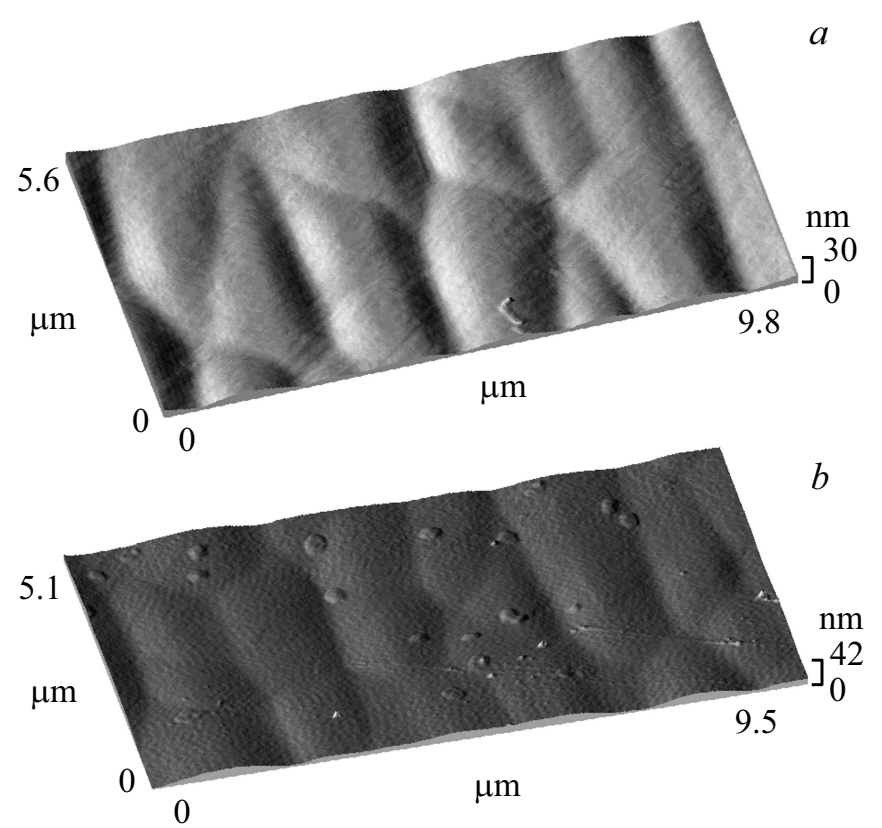

Рис. 3. Характерная картина рельефа поверхности GaAs между контактами: $a-$ до облучения, $b-$ после воздействия быстрыми нейтронами флюенсом $0.5 \cdot 10^{15} \mathrm{~cm}^{-2}$ и последующего частичного отжига.

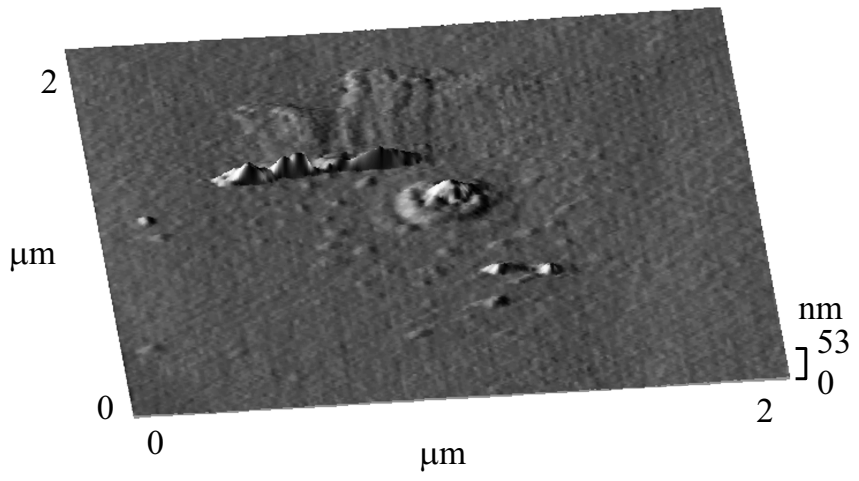

Рис. 4. Изображение крупных кластеров радиационных дефектов, полученное с помощью методики АСМ.

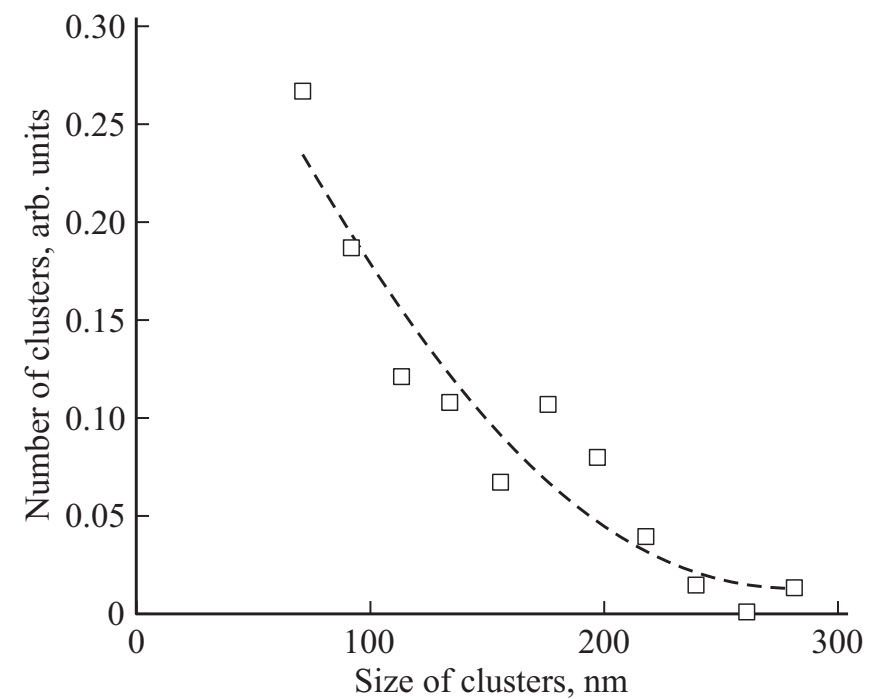

Рис. 5. Распределение по размерам разупорядоченных областей, образовавшихся при облучении быстрыми нейтронами GaAs: линия - расчет с использованием TRIM, точки результат обработки зондовых измерений.

На рис. 4 представлено полученное в работе изображение крупных кластеров радиационных дефектов.

По результатам АСМ-измерений проводился анализ размеров (рис. 5) и количества образовавшихся объемных радиационных дефектов. После сегментации изображения с вычитанием скользящего фона [9] в расчет принимались только те связные области, которые состояли как минимум из 9 точек - обнаружение более мелких объектов считалось недостоверным. За эффективный размер обнаруженного после облучения объекта с номером $i$ принимался диаметр круга $d_{i}=2 r_{i}$, где $r_{i}=\sqrt{S_{i} / \pi}-$ радиус круга, $S_{i}$ - площадь $i$-й связной области.

Спектр первичных атомов, получивших энергию от нейтронов, имеет колоколообразный вид (рис. 6). Мелкие кластеры в эксперименте не разрешались, однако, как минимум, часть их, согласно теоретическим представлениям, должна была разрушиться при нагреве, что увеличивает точность оценки числа формирующихся 


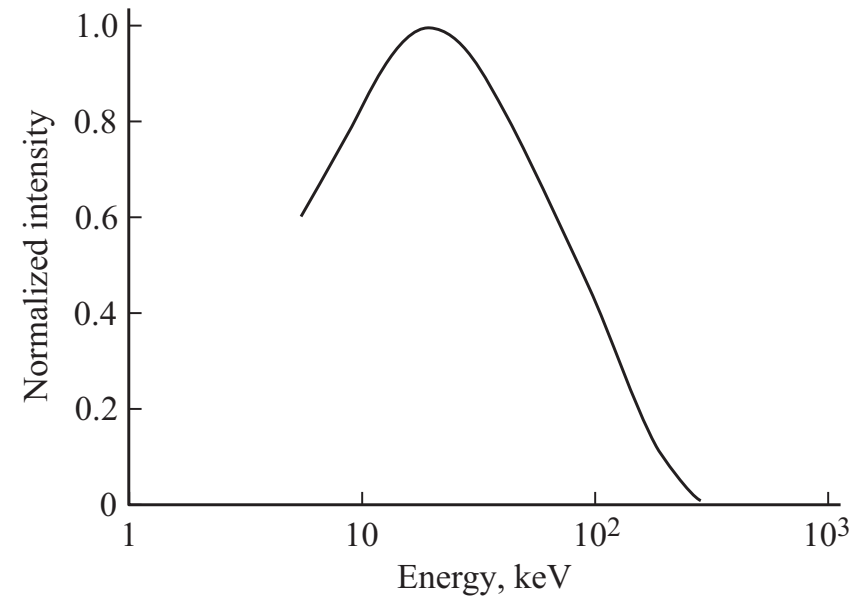

Рис. 6. Рассчитанный в модели твердых шаров [10] спектр первичных атомов $\mathrm{Ga}$, получающих энергию при соударениях с нейтронами.

разупорядоченных областей с использованием методики анализа микрорельефа поверхности.

По глубине активной области использованной в работе структуры $(90$ нм) укладывалось не более одного КРД, поэтому зондовые исследования микрорельефа поверхности в совокупности с результатами измерений электрофизических параметров позволили оценить среднее значение величины области пространственного заряда кластеров, которое составило 37 нм.

Результаты работы могут быть использованы для моделирования параметров полупроводниковых приборов из GaAs после нейтронного облучения. Полученные в ходе исследований данные говорят о высоком качестве изготовления использованной структуры и возможности ее применения в специализированной радиационно стойкой аппаратуре.

\section{Финансирование работы}

Работа профинансирована Министерством науки и высшего образования РФ в рамках государственного задания Нижегородского государственного университета им. Н.И. Лобачевского (проект № 0729-2020-0035).

\section{Конфликт интересов}

Авторы заявляют, что у них нет конфликта интересов.

\section{Список литературы}

[1] Т.М. Агаханян, Е.Р. Аствацатурьян, П.К. Скоробогатов. Радиационные эффекты в интегральных микросхемах (М., Энергоатомиздат, 1989).

[2] Ф.Ф. Комаров. УФН, 187 (5), 465 (2017).

[3] Ф.Ф. Комаров. УФН, 173(12), 1288 (2003).

[4] С.В. Оболенский. Поверхность. Рентгеновские, синхротронные и нейтронные исследования, № 7, 53 (2003).
[5] Е.А. Тарасова, А.В. Хананова, С.В. Оболенский, В.Е. Земляков, Ю.Н. Свешников, В.И. Егоркин, В.А. Иванов, Г.В. Медведев, Д.С. Смотрин. ФТП, 50 (3), 331 (2016).

[6] A.B. Loginov, R.R. Ismagilov. J. Nanophotonics, 11 (3), 1 (2017).

[7] A.B. Loginov, R.R. Ismagilov, A.N. Obraztsov, I.V. Bozhev, S.N. Bokova-Sirosh, E.D. Obraztsova, B.A. Loginov. Appl. Surf. Sci., 494, 1030 (2019).

[8] Б.А. Логинов, П.Б. Логинов, В.Б. Логинов, А.Б. Логинов. Наноиндустрия, 12 (6) [92], 352 (2019).

[9] Р. Гонсалес, Р. Вудс. Цифровая обработка изображений (М., Техносфера, 2012).

[10] В.С. Вавилов. Действие излучений на полупроводники (М., Физматгиз, 1963).

Редактор Л.В. Шаронова

\section{Experimental studies of characteristics modifications of GaAs structures with Schottky contacts after fast neutron impact}

E.V. Volkova ${ }^{1}$, A.B. Loginov' ${ }^{2}$, B.A. Loginov' ${ }^{3}$, E.A. Tarasova ${ }^{1}$, A.S. Puzanov ${ }^{1}$, S.A. Korolev', E.S. Semyonovykh ${ }^{1}$, S.V. Khazanova ${ }^{1}$, S.V. Obolensky ${ }^{1}$

${ }^{1}$ Lobachevsky State University of Nizhny Novgorod, 603950 Nizhny Novgorod, Russia

${ }^{2}$ Lomonosov Moscow State University, 119991 Moscow, Russia

${ }^{3}$ National Research University "MIET", 124498 Zelenograd, Moscow, Russia ${ }^{4}$ Institute for Physics of Microstructures, Russian Academy of Sciences, 603950 Nizhny Novgorod, Russia

Abstract The electrophysical parameters and surface morphology of GaAs $n / n^{-}$structures with Schottky contacts before and after neuron impact with an average energy of about $1 \mathrm{MeV}$ were studied. Changes in the profiles of the concentration and mobility of electrons in the structures were determined by the capacitancevoltage measurements. The method of atomic force microscopy helped to find radiation defect clusters appearing during impact. A complex approach to the determination of their parameters is proposed. 